\title{
Primary Exploration of Culture Teaching Reform Based on Multimedia
}

\author{
Fan Jufan \\ School of Foreign Studies, Xi'an University, 710065
}

Keywords: Multimedia; Culture Teaching; Reform

Abstract: Along with gradual promotion and popularization of computer technology and network technology, using computer-related technology to assist teaching has become the general trend of teaching reform. Multimedia teaching has been applied more and more in education and teaching due to its characters such as visualization, vividness, strong interactivity, etc. Practical teaching shows that the application of multimedia technology has effectively enhanced quality of education and teaching. This paper makes a brief analysis of the present situation of culture teaching and brings forward the idea of culture teaching reform based on multimedia.

\section{Introduction}

Multimedia teaching, which started late in China, has gradually appeared in late 1980s. Form and content of the original multimedia teaching, mainly shown in the form of PowerPoint, projector, video and audio recording, are relatively simple. In early development stage of multimedia teaching, due to the huge contrast between input and output, many colleges and universities were still cautious about multimedia teaching. The investment in a multimedia classroom, which often cost tens of thousands, meant a large sum of money for many colleges and universities at that time. Nowadays, with the investment of colleges and universities in education and teaching increasing, multimedia-facilitated classroom and multimedia teaching are no longer unfamiliar for most teachers and students. With the help of information technology, multimedia teaching is no longer limited to illustrated pictures and texts but moving towards deeper and wider fields of education and teaching. The English word "multimedia" is composed of two parts: "multi" and "media”. Media, in certain sense, is a medium, a bridge, and a means to realize information exchange between people. Therefore, the most significant advantage of multimedia teaching lies in its interactivity, which will process education and teaching information, such as test, image, audio, etc., with computer and information methods, and makes the accessible information a kind of comprehensive teaching resources.

\section{Present Situation of Multimedia Teaching in Colleges and Universities}

For a long time, there has always been a debate about the superiority between multimedia and traditional teaching, and about which teaching method is more suitable for China's higher education. In fact, multimedia teaching and traditional teaching have their own unique features, and the two 
teaching methods can be alternatively applied to different courses or education and teaching content. But overall, the writer believes that multimedia teaching has more obvious advantages.

The traditional teaching mode, often composed of a blackboard and a stick of chalk, is easy to implement, and the teachers only need to perfunctorily teach the students step-by-step, according to content stipulated in the teaching material. Under the traditional teaching mode, due to limitation of class time and classroom capacity, the teachers generally don't have to look for supporting teaching materials and procedures, such as courseware making, etc. Progress of class are completely controlled by the teachers, and accordingly the teachers become the core of the whole class. What's more, there's even no need for simple interaction between teachers and students. When carrying out teaching process on a certain subject, the teachers explain points in the textbooks to the students unidirectionally, sometimes even complete all calculations and inferences all by their own, which has kept the students off the independent exploration. Therefore, the disadvantages of traditional education and teaching are obviously seen. Such kind of unidirectional knowledge infusion is not conductive for developing independent learning ability and cultivating exploration spirit of the students, and under such unidirectional condition, there's not enough communication between the students and the teachers, which makes the teachers unable to master learning status of the students. Teacher' position in the traditional teaching brings some fearful feelings to the students, so they usually regard the teacher as an absolute authority and the classroom atmosphere always seems to be oppressive. Such situation goes against students' enhancement of comprehensive abilities and formation of ability to solve problems independently. If this continues, teachers' teaching process will inevitably become stylization, students' learning process will also unavoidably turn out to be boring and they will gradually lose motivation and interest in study.

Multimedia-assisted teaching has put forward higher requirements for personal ability of teachers and students. Teaching based on multimedia has realized dynamic interaction between teachers and students, which requires adequate preparation for course, even course-related content. For the teachers, they have to make plenty of preparatory work before teaching, which will be a tedious and collar work for them. Multimedia-assisted teaching method is not so difficult for science and engineering teachers, but for literal arts teachers, since plenty of supporting software will be used during production of multimedia courseware. Due to the education system of China, liberal arts teachers, who often graduate from normal colleges and universities, are not familiar with the use of computer tools. Therefore, multimedia teaching sets all-around and high-standard requirements for teachers. The amount of information received by the students under the multimedia classroom teaching environment is not of the same magnitude when comparing with traditional teaching. With the abstract knowledge shown and demonstrated in the form of visualized and materialized by means of the multimedia, the students are encouraged to understand complex questions easily and master important and difficult knowledge in a short time. At the same time, the complex teaching process are simplified and maximize intensity of knowledge. As it is seen, multimedia teaching method can easily catch interest points of the young students, stimulate learning interest and learning enthusiasm of the students, and indirectly enhance learning initiative of the students. Multimedia teaching is obviously superior to traditional teaching mode regarding learning initiative of the students in class. The direct consequence resulting from enhancement of students' enthusiasm is that the classroom atmosphere has been obviously improved.

Relevant documents issued by Ministry of Education pointed out that, at present, the proportion of multimedia teaching hours shall not be lower than fifteen percent in colleges and universities and shall not be lower than thirty percent in the 211 institutions. However, according to investigations and surveys, many multimedia applications in our colleges and universities have become mere formality. Quite a few courses have been applied merely for the purpose of multimedia application without much breakthrough in specific application form and teaching content. Many teachers just 
replace traditional blackboard and chalk with PPT and call this as multimedia teaching. Some schools don't have complete supporting facilities and the multimedia system is not systematic. Some teachers, who prefer easy jobs, avoid production of complex multimedia courseware. They either copy some ready-made courseware online or make courseware with greatly reduced quality. These are all negative factors which have restricted development of multimedia teaching in our colleges and universities.

\section{Culture Teaching Reform Strategy Based on Multimedia}

As mentioned above, at present, the problems in culture teaching not only exists in individual subjects, but also a common phenomenon. The writer has been engaged in culture teaching for many years and has carried out long-term tracking and careful study on the combination of multimedia instrument and culture teaching in colleges and universities. The writer believes that, currently reform of culture teaching by means of multimedia in our colleges and universities shall focus on the following aspects:

\subsection{Strive to Improve Teaching Idea of Most teachers}

Modern information technology has achieved tremendous development. Multimedia-assisted teaching, which is closely connected with computer, informatization and digital technology have become one of the most important supplementary means for present teaching in colleges and universities. In-depth development of teaching by using multimedia, which we can think as a digitized new teaching method, has overturned the traditional teaching framework in the form. Culture itself is a relatively abstract concept, and we can easily and quickly convey information, which can't be precisely conveyed through traditional teaching method to students in the form of multimedia mode. For example, under multimedia condition, we can not only present concept and connotation of culture, but also can describe culture with audio, video instruments. As the teaching guide, the teachers must set up brand new teaching idea and shall be good at applying the teaching equipment. In addition, the teachers shall design and make multimedia courseware, which is suitable for their own characteristics, according to their own condition, and shall thoroughly combine advantages of modern teaching methods with traditional teaching methods. Meanwhile, the teachers shall mentally put themselves to the right position, properly deal with positioning relationship between the students and themselves in class, and thoroughly integrate the teachers' guiding function with the students' main body role in order to achieve optimization of teaching results.

\subsection{Combine New with Old and Make the Best of the Both}

Whether the traditional culture teaching method or the teaching method based on multimedia both have their respective advantages and disadvantages. Thus, we must be good at making choice under different condition and shall combine the new teaching method with the old teaching method to the great advantage. Culture teaching based on multimedia must absorb the essences of the traditional teaching method, but that is not to take a negative attitude blindly and think that new method is always better than old one. Only in this way, can the new and old teaching methods effectively be improved one another.

\subsection{Make Strict Production Standards for Multimedia Courseware}

Multimedia courseware is the most basic element in multimedia teaching system. Multimedia 
courseware production can't be neglected if we want to achieve expected effects in teaching. At present, the standards of multimedia courseware production vary greatly from institution to institution, from major to major, and even from teacher to teacher. Bluntly speaking, quantity of many courseware is not high. This has aroused alertness of many experts, and how to standardize multimedia courseware production standards has entered into discussion now. Multimedia courseware generally contains three elements: teaching content, teaching process design and artistry. We can qualify these and finally establish strict standards. Only the courseware that meets the requirements can be approved to enter teaching process. Through such systematic constraint, we can practically improve production quality of multimedia courseware and encourage the teachers to improve production quality of their courseware. School shall vigorously promote courseware to high quality, which makes the teachers have a clear understanding and intuitive feeling for the standards and brings the multimedia courseware production to the right path of good quality and artistry.

\subsection{Continue to Increase Investment in Teaching}

Culture teaching doesn't have much difference from teaching of other subjects. The requirements of the multimedia platform, which is applied by culture teaching, for the whole system is not highly made. But in the previous years, due to reasons like funding, etc, the classroom with multimedia teaching system was not imperfectly constructed. At present, colleges and universities make investment in multimedia classroom and hardware as a kind of remedy to the past years. The modern teaching system must be supported by modern teaching facilities. Schools shall rationalize capital allocation on the basis of the number of persons of the school and characteristics of the courses and bring building of the multimedia classroom and corresponding hardware into the focused scope. Also, maintenance and management of multimedia classroom must be strengthened accordingly to ensure normal operation of equipment and convenient use of the students in the classroom. Aging equipment must be updated in time and equipment archives system must be established for purpose of management, to gradually improve various rules and regulations.

\subsection{Enhance Technical Training}

As one of modern teaching supplementary means, multimedia puts forward higher operating requirements for teachers and students. Teachers and students must have professional knowledge to use the equipment and make the equipment perform thoroughly and efficiently. Technical training for the teachers is an important part for enhancing multimedia teaching quality. As far as I know, most teachers engaged in culture teaching are liberal arts graduates and have different difficulties and problems when they use computer and communication equipment, which bring them obvious disadvantage when compared with science and engineering teachers. Meanwhile, teachers engaged in culture teachings often feel discouraged when making courseware. They have good ideas that are hard to fulfill, so they have to consult teachers of other subjects. It's very necessary for the schools to set up organized and scale-formed training on multimedia operation and courseware production for the teachers.

\subsection{Establish the Effectiveness Evaluation Standard for Multimedia Teaching}

A scientific and objective evaluation standard is necessary for evaluating multimedia teaching from the aspect of teaching effectiveness. This evaluation standard must be practicable and easy to implement, which will play an important directive role in course teaching. Evaluation standard for culture teaching based on multimedia must be fully reflected in such aspects as teaching content, 
important and difficult points, and scientifically designed structure.

\section{Conclusion}

Although multimedia teaching has been widely applied in China and has brought great vitality for culture teaching in colleges and universities, but during its development and growth, it also has encountered some problems. We can't neglect existence of these problems when we see these achievements. Only through continuous optimizing and constant innovation of multimedia teaching methods, and on the basis of exploration, conclusion and enhancement, can we take effective measures to promote the health development of teaching by means of multimedia.

\section{References}

[1] Shan Xiaoxin: Research on Resolution Strategy for Predicament Facing by College and University Teaching Reform [J]. New Curriculum Research (Midmonth-Double). 2017 (1)

[2] Song Tian: Guide Higher Engineering Education and Teaching Reform with Result-Oriented Education Concept [J]. China University Teaching. 2015 (1)

[3] Wang Zhixian, Wang Guanxiang: Constructing Multimedia Teaching System by Using Diskless Technology [J]. China Modern Educational Equipment. 2017 (9)

[4] Wu Jing: Discussion on the Application of Multimedia Technology in Ancient Literature Classroom Teaching [J]. Higher Education Exploration. 2017 (01)

[5] Ye Doudan, Zhang Tianzhu, Huang Xiaowei, etc.: Changing Educational Thoughts and Promoting the Reform of Education and Teaching in Colleges and Universities [J]. J Changchun Univ Tradit Chin Med. 2017, 33 (3)

[6] Zeng Lusheng, Cui Dejie: Give Full Play to the Advantages of Multimedia Teaching to Improve the Teaching Quality of Young Teachers [J]. Education Teaching Forum. 2017 (48) 